Int. J. Electrochem. Sci., 13 (2018) 11829 - 11838

\title{
Copper Electrodeposition on Polyimide Substrate Using Polyaniline Film as a Seed Layer for Metallization of Flexible Devices
}

\author{
Dohyeun Lee ${ }^{1}$, Taeho $\mathrm{Lim}^{2}$, Hana Lim ${ }^{3}$, Hyun-Jong Kim ${ }^{3, *}$ and Oh Joong Kwon, ${ }^{1, *}$ \\ ${ }^{1}$ Department of Energy and Chemical Engineering, Innovation Center for Chemical Engineering, \\ Incheon National University, 119 Academy-ro, Yeonsu-gu, Incheon 22012, Republic of Korea \\ ${ }^{2}$ Department of Chemical Engineering, Soongsil University, 369 Sangdo-ro, Dongjak-gu, Seoul \\ 06978, Republic of Korea \\ ${ }^{3}$ Surface Technology Center, Korea Institute of Industrial Technology (KITECH), 156 Gaetbeol-ro, \\ Yeonsu-gu, Incheon 21999, Republic of Korea \\ *E-mail: hjkim23@kitech.re.kr, ojkwon@inu.ac.kr
}

doi: $10.20964 / 2018.12 .56$

Received: 19 August 2018 / Accepted: 16 September 2018 / Published: 5 November 2018

The Metallization of flexible printed circuit boards is a key issue for the fabrication of flexible devices. In this study, $\mathrm{Cu}$ electrodeposition was performed on a flexible polyimide substrate using polyaniline film as a seed layer for the first time. A conductive polyaniline film was formed on the surface of the polyimide substrate by dip and spin coating methods. It was revealed that the spin coating method was advantageous in forming a uniform and continuous polyaniline film because it reduces the secondary nucleation of polyaniline by removing excess reactants from the polyimide substrate. Pd nanoparticles were also introduced onto the polyaniline-deposited substrate to promote $\mathrm{Cu}$ nucleation during the $\mathrm{Cu}$ electrodeposition process. With the aid of polyaniline film and $\mathrm{Pd}$ nanoparticles, a continuous and uniform $\mathrm{Cu}$ film was successfully deposited on a polyimide substrate.

Keywords: Flexible printed circuit board, electrodeposition, polyaniline, palladium, seed layer, copper

\section{$\underline{\text { FULL TEXT }}$}

(C) 2018 The Authors. Published by ESG (www.electrochemsci.org). This article is an open access article distributed under the terms and conditions of the Creative Commons Attribution license (http://creativecommons.org/licenses/by/4.0/). 